\title{
Backwater Rise Due to Bridge Piers in Curved Channels under Subcritical Flow Conditions
}

\author{
Amir M. Mobasher and Ahmed H. Mahmoud \\ Civil Engineering Department, Faculty of Engineering, Al-Azhar University, Cairo, Egypt
}

Correspondence Author: Amir M. Mobasher, Civil Engineering Department, Faculty of Engineering, Al-Azhar University, Cairo, Egypt E-mail: dr_amir_mobasher@yahoo.com

Received date: 22 December 2018, Accepted date: 22 January 2019, Online date: 5 February 2019

Copyright: (c) 2018 Amir M. Mobasher and Ahmed H. Mahmoud. This is an open-access article distributed under the terms of the Creative Commons Attribution License, which permits unrestricted use, distribution, and reproduction in any medium, provided the original auth or and source are credited.

\begin{abstract}
The construction of bridges across rivers is challenging, as bridge piers act as obstacles to waterways and cause a narrowing of the natural channel. Therefore, it is critical to know the increase in water surface elevation due to bridge constrictions, particularly during flood events. In the past more researchers have a try to improve experimental equations based on the perception of mechanics of backwater rise. However most of the investigators have discussed the backwater rise at bridge pier located in a straight channel and no study has been discussed when bridge pier is located in a curved channel.

Our study showed that, backwater rise is studied both in straight channel and in a rectangular curved channel having a central angle of $30^{\circ}$ for subcritical flow condition, which is the type of flow that exists in most rivers. A different pier shapes were located in the straight channel, moreover in divisions 0,15 and 30 degrees in the curved channel. This research observed that the values of backwater rise at the curved channel are bigger than those of straight channel, the maximum backwater rise occurs at section 0 degrees and the minimum occurs at section 30 degree of the curved channel.
\end{abstract}

Keywords: Backwater Rise, Bridge piers, curved channel, waterways.

\section{INTRODUCTION}

Bridge piers form obstructions to the flow in an open channel. The flow contracts between piers, and resulting effect of contraction and obstruction is that a backwater (heading-up) is created upstream of the piers.

It is always desirable to keep the resulting amount of heading-up $h$ as small as practicable. Relatively large values of $h$ endanger the adjacent territories of land being clogged due to rise of water table caused by the elevated level of water in the upstream channel. Moreover, for the case of bridges in large channels like rivers, if the heading-up is not reasonably estimated, the flood protection costs may be increased (Soliman, 1989).

This backwater rise is controlled fundamentally upon its geometric shape; it's local in the stream, the amount of flow, and the channel contraction proportion (Chow, 1959).

Discussion of how bridge piers effects channel impediment and hydraulic effectiveness is a significant case in bridge planning. More researchers have a try to improve analytical, semi-experimental or experimental equations for backwater rise due to bridge piers located in straight channels. As illustrated by Henderson (Henderson, 1966) and (Sturm, 2001), the survey of backwater rise may be caused to flow retraction due to bridges piers was being by Yarnell (Yarnell, 1934). Moreover, the backwater rise upstream bridges was studied by Atabay et al. (Atabay et al., 2018) Beffa (Beffa, 1996), Charbeneau et al. (Charbeneau and Holly, 2001; El-Alfy, 2006; El-Alfy, 2009; Hunt and Brunner, 1995; Kaatz, 1997;Seckin, 2004; Smibabu et al., 2011; Soliman, 1989).

However, no studies were conducted in curved channels. Accordingly, this research was initiated with the objective of studying the backwater rise due to bridge piers in curved channels, experimentally for subcritical flow condition, which is the type of flow that exists in most rivers. The empirical finding on backwater at different pier shapes position of among departments in a 30 degree curved channel is presented. In order to understand the effect of the curvature on the backwater, the finding is dissimilarity between with those in straight channel. The data of the backwater rise may be caused to constriction of flow by bridge piers presented in this study paper are utilize in evaluation of a new formula, which could be applied in calculate backwater rise at subcritical flows among bridge piers in curved channels. 


\section{THEORITICAL BACKGROUND}

Fig. 1 shows the definition sketch for the flow between bridge piers. In the plan, b1 is the distance C.L. to C.L. of two piers, $b 2$ is the clear distance between piers, $L$ is the length of the pier and $t$ is the pier thickness. In the elevation, $d 1, d 2, d 3$ are the depths of flow upstream, in between and downstream respectively, $\mathrm{d} 1$ represents the increased upstream depth due to the backwater effect, while $\mathrm{d} 3$ is the normal depth of flow before construction of piers. The heading-up $\mathrm{h}$ is represented by the value $\left(d_{1}-\mathrm{d} 3\right)$. The depth $\mathrm{d} 2$ depends on the state of flow between piers (i.e., whether the flow is subcritical or supercritical).

The energy equation between sections $2 \& 3$ (Fig. 1) can be written as:

$$
\varepsilon\left[d_{2}+\frac{V_{2}^{2}}{2 g}\right]=\left[d_{3}+\frac{V_{3}^{2}}{2 g}\right]
$$

Where $\varepsilon=\%$ energy recovery between sections $2 \& 3$, e. g., if the energy loss between the two sections is $10 \%$, then $\varepsilon=0.90$, and so on.

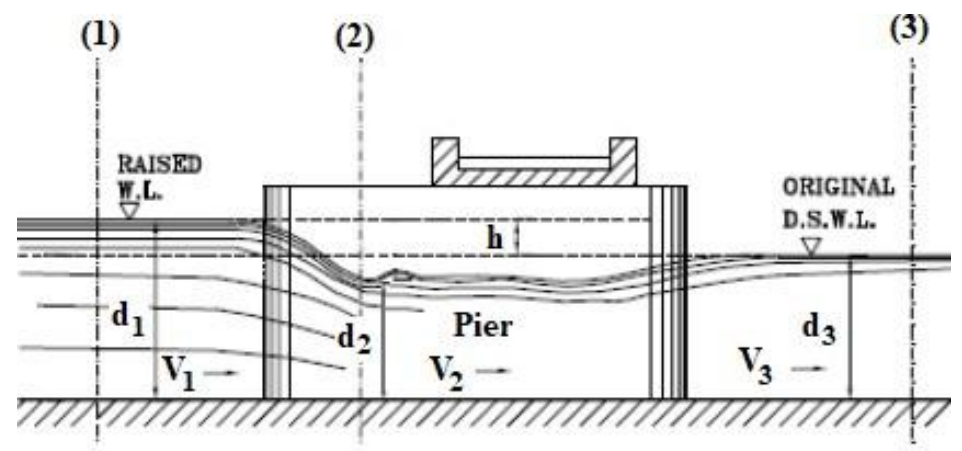

(1)

(2)

(3)

\section{Elevation}

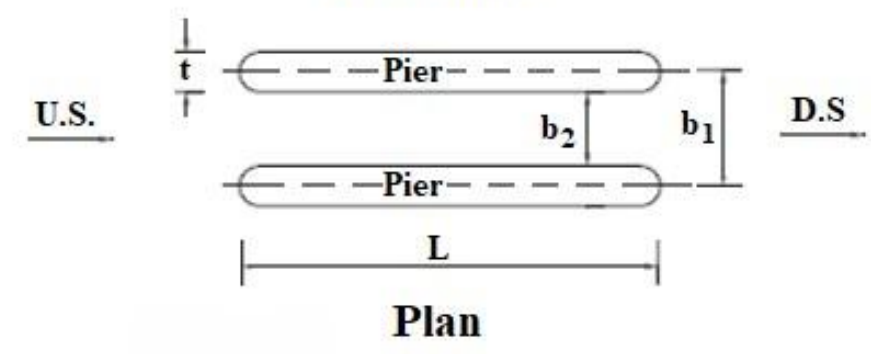

Fig. 1: Flow between bridge piers.

Equation 1 can be written as:

$$
\varepsilon\left[d_{2}+\frac{V_{2}^{2} \cdot d_{2}}{2\left(\sqrt{g d_{2}}\right)^{2}}\right]=\left[d_{3}+\frac{V_{3}^{2} \cdot d_{3}}{2\left(\sqrt{g d_{3}}\right)^{2}}\right]
$$

Thus,

$$
\varepsilon \cdot d_{2}\left[2+F_{r_{2}}^{2}\right]=d_{3}\left[2+F_{r 3}^{2}\right]
$$

Where Fr2 and Fr3 are the Froud numbers at sections 2 and 3, respectively. From Continuity principle, we have:

$$
\mathrm{V}_{2} \cdot \sigma \cdot \mathrm{b}_{1} \cdot \mathrm{d}_{2}=\mathrm{V}_{3} \cdot \mathrm{b}_{1} \cdot \mathrm{d}_{3}
$$

Where $\sigma$ is called the "contraction ratio $=\mathrm{b} 2 / \mathrm{b} 1$ ".

According to Soliman (Soliman, 1989), Eqs. 1, 2, 3 and 4 could be consummated in the following relationship: 


$$
\sigma^{2}=\frac{\varepsilon^{3} \cdot F_{r 3}^{2}\left[2+F_{r_{2}}^{2}\right]^{3}}{F_{r_{2}}^{2}\left[2+F_{r 3}^{2}\right]^{3}}
$$

Now if the flow at section 2 (Fig. 1) is critical, the Fr2 $=1$. The value of Fr3 which satisfies this condition is called "the limiting value of Froud number at section 3", and is denoted by Fr3L. This means that for given contraction ratio $\sigma$, the flow between piers will be subcritical or supercritical depending on whether the value of Fr3 is smaller or greater than Fr3L.

According to the preceding discussion, if $\operatorname{Fr} 2=1$ is substituted in 5, we would have:

$$
\sigma^{2}=\frac{27 \cdot \varepsilon^{3} \cdot\left[\left(F_{r_{3}}\right)_{L}\right]^{2}}{\left[2+\left(F_{r_{3}}\right)_{L}^{2}\right]^{3}}
$$

Under subcritical flow condition, the velocity distribution across the spaces between piers is nonuniform. For this reason, it would have been a reasonable approach if a momentum equation were applied between sections 1 and 3 (Fig. 1) such that (M1 M3 = F), where M1 and M3 are the momentum at sections 1 and 3, respectively and F is the drag force on piers. However, the estimation of F, if piers are considered as flat plates, can never be exact be- cause the pier nose and tail must have a role in the problem.

Yarnell (Yarnell, 1934) obtained experimental results for different types of piers, which are expressed in the following empirical equation:

$$
\frac{h}{d_{3}}=K \cdot F_{r_{3}}^{2}\left(K+5 F_{r_{3}}^{2}-0.60\right) \cdot\left(\alpha+15 \alpha^{4}\right)
$$

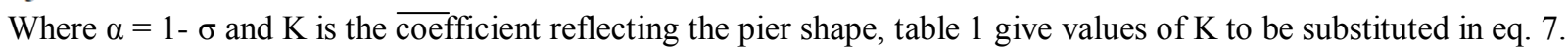

Table 1: Shape coefficients (Yarnell, 1934).

\begin{tabular}{|l|c|}
\hline \multicolumn{1}{|c|}{ Pier shape } & Shape coefficient "K" \\
\hline Semicircular nose and tail & 0.90 \\
\hline Triangular nose and tail & 1.05 \\
\hline Square nose and tail & 1.25 \\
\hline
\end{tabular}

\section{THEORITICAL APPROCH}

Theoretical study has been behaved utilizing dimensional analysis method to discover the relationships among the different measurements and changes for interaction between all pier shapes and locations. All parameter and geometry are defined in Fig. 2.

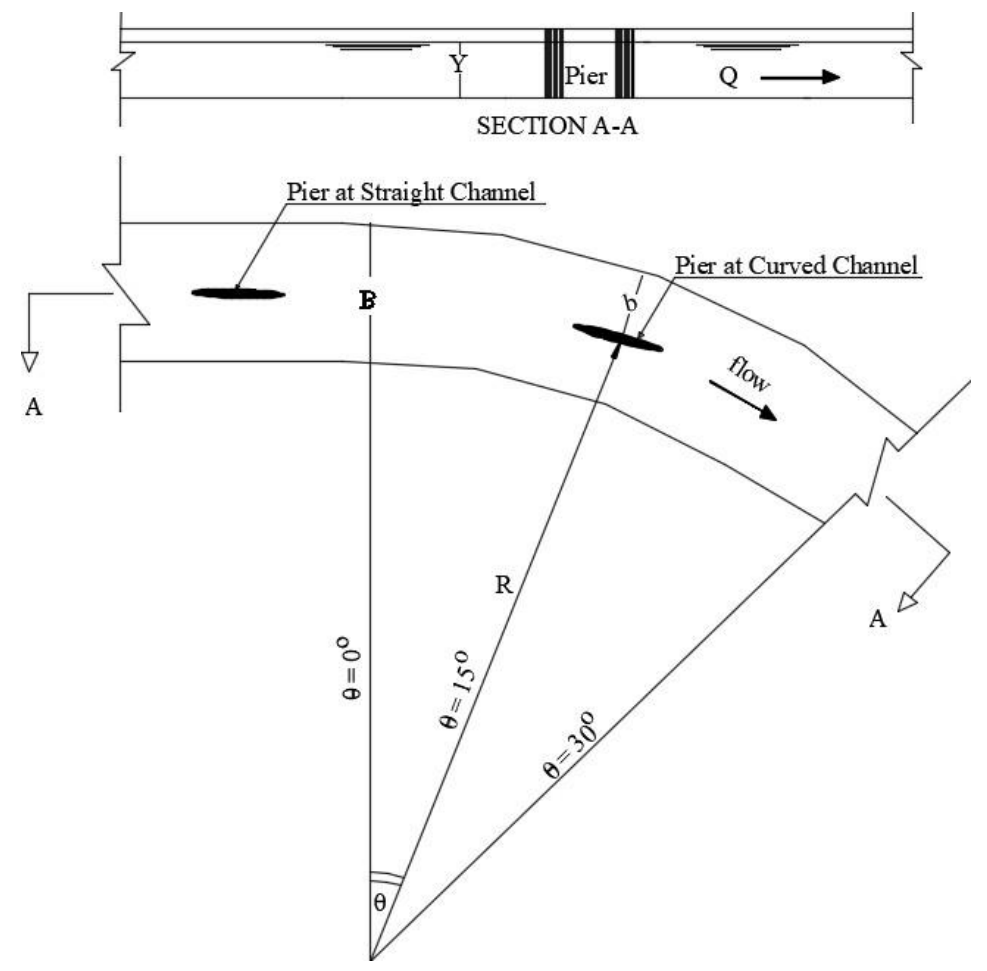




\section{Fig. 2: Definition sketch of all parameters.}

Functional relationships are obtained between the relative depths of the backwater rise $\mathrm{h}$ for all parameter.

In this study: the Backwater rise $\mathrm{h}$ is the dependent variable. It can be expressed as a function of all other independent variables as follows:

$$
\mathrm{h}=\phi(\mathrm{B}, \mathrm{R}, \mathrm{b}, \mathrm{t}, \mathrm{L}, \mathrm{y}, \mathrm{K}, \Theta, \mathrm{Q}, \rho, \mathrm{g}, \mu,)
$$

where, $\mathrm{B}$ is the channel width, $\mathrm{R}$ is the radius of channel, $\mathrm{b}$ is the amount of space between two things from pier to channel side, $\mathrm{t}$ is the thickness of the pier in the center, $\mathrm{L}$ is the length of the pier, $\mathrm{y}$ is the normal water depth, $\mathrm{K}$ is the coefficient reflecting the pier shape, $\Theta$ is the degree of the curved channel, $Q$ is the discharge, $\rho$ is the density of fluid, $g$ is the gravity acceleration and $\mu$ is the dynamic viscosity.

Using Buckingham's $\pi$-Theorem, nine variables and two repeated changes were obtained. These changes can be easily coordinated in the following non -dimensional $\pi$-terms.

$\pi 1=\mathrm{h} / \mathrm{y}, \pi 2=\mathrm{B} / \mathrm{y}, \pi 3=\mathrm{b} / \mathrm{y}, \pi 4=\mathrm{t} / \mathrm{y}, \pi 5=\mathrm{L} / \mathrm{y}, \pi 6=\mathrm{R} / \mathrm{B}, \pi 7=\mathrm{K}, \pi 8=\mathrm{\theta}, \pi 9=\mathrm{Q}^{2} / \mathrm{B}^{5} \mathrm{~g}$ According to Buckingham Pitheorem, the general form of relationship between these variables is written as follows:

$$
\phi=\left(\frac{h}{y}, \frac{B}{y}, \frac{b}{y}, \frac{t}{y}, \frac{L}{y}, \frac{R}{y}, \frac{Q^{2}}{g B^{5}}, K, \theta\right)=0
$$

Taking the properties of $\pi$-terms into account, the following relationship was obtained:

$$
\phi_{1}=\left(\frac{h}{y}, \frac{b}{B}, \frac{L}{t}, \frac{R}{t}, F r, K, \theta\right)=0
$$

Finally, the following function was established:

$$
\frac{h}{y}=\phi_{1}\left(\frac{b}{B}, \frac{R}{t}, \frac{L}{t}, F r, K, \theta\right)
$$

\section{EXPERIMENTAL WORK}

\section{Channel Description}

An experimental study was conducted in a new re-circulating channel of $8 \mathrm{~m}$ long and $60 \mathrm{~cm}$ width and $30 \mathrm{~cm}$ high with visible clear polycarbonate sides to allow visual observation of the water surface (Fig. 3). The flume encompasses three parts, the first and last parts are $3 \mathrm{~m}$ long while the third part is the middle curved part with an angle of $30^{\circ}$ in the horizontal direction. A sharp crested triangular weir at the downstream of the return channel was used to measure the discharge. Water was supplied from a sump into the entrance basin. Water level in the channel was controlled by a tail gate situated at the end of channel.

The pier models of different shapes for different contraction ratios $0.93,0.95$ and 0.97 are made using wood, and three pier length /pier width ratios (L/t) were tested (i.e. 5, 6.67 and 10). The shapes are rectangular, triangular and semi-circular nose and tail.

The pier was located in section 0, 15 and 30 degree from the beginning of the curved channel and also in the middle of upstream straight channel separately. 


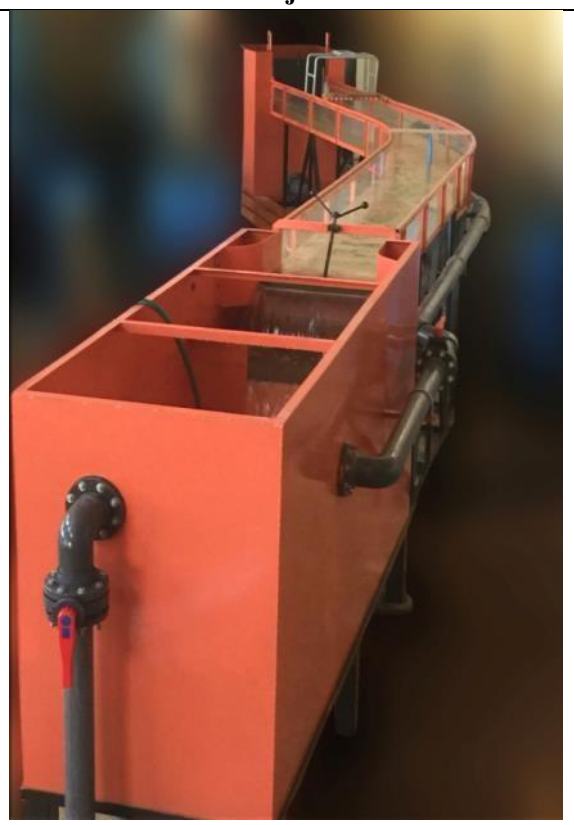

Fig. 3: The experimental channel.

Experiments were conducted under clear-water conditions at four different water discharges 12.75, 18.45, 23.77 and 29.14 lit/sec and the Froude number was ranged between 0.14 and 0.32 , just downstream. The depth of flow in all the experiments was constant and equal to $13 \mathrm{~cm}$.

\section{Depth and Velocity Distribution Measurements}

The flow depths was measured by using a point gauge allowing measurements accuracy of $\pm 0.1 \mathrm{~mm}$, and velocity was measured locally at various points (i.e. at different depths along the water depth). For tracing the velocity distribution at any sections, a mini flow meter, with outer diameter $7.0 \mathrm{~mm}$, was used to find the velocity in the horizontal direction $(\mathrm{Hz})$ in $\mathrm{cm} / \mathrm{sec}$ based on a calibration curve for this apparatus, as indicated photos.

\section{The Measured Parameters}

The following parameters were measured for each run; upstream flow depth (d1), approach velocity (V1), flow depth through vents $\left(\mathrm{d}_{2}\right)$, flow velocity through vents $\left(\mathrm{V}_{2}\right)$, downstream flow depth (d3); and downstream flow velocity (V3). Sample of experiments is illustrated through Fig. 4.
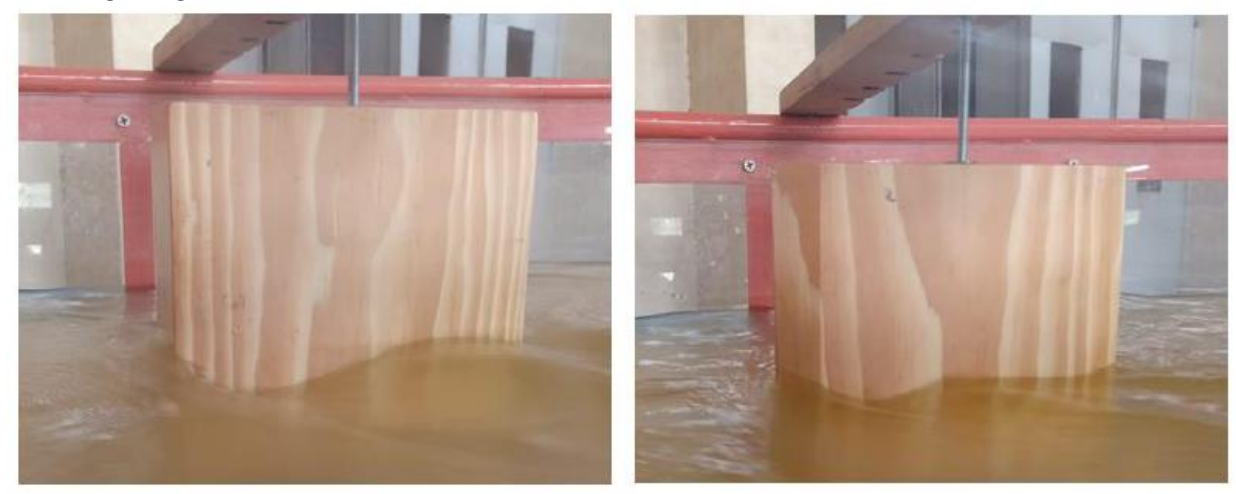

Fig. 4: Photos for backwater rise under subcritical flow condition between piers.

\section{RESULTS AND OBSRVATIONS}

Results of the backwater rise upstream the pier situated at various sections of the channel down different flow conditions with different pier shapes are presented here. In this study effect of the increasing in Froud number (Fr) resulted from the increasing of flow discharge $(\mathrm{Q})$ on the backwater rise is investigated.

The downstream flow parameters (d3, V3) are used in computing the value of Froude number (Fr3). The downstream Froude number (Fr3L) conformable to critical flow conditions between piers for each worth of contraction ratio $(\sigma)$ is calculated from Eq. 7 be controlled on each run information. If the value of Fr3 is lower than the value of Fr3L, the flow between piers is subcritical. The dimensionless backwater rise $(\mathrm{h} / \mathrm{d} 3)$ may be caused to subcritical flow between bridge piers is observed through Figs. 5 to 14. 


\section{Effect of pier Location on The backwater Rise}

Figs. 5, 6 and 7 represent relationship between dimensionless backwater rise $(\mathrm{h} / \mathrm{d} 3)$ and $\mathrm{Fr} 3 / \mathrm{Fr} 3 \mathrm{~L}$ for different pier Locations under subcritical condition. for flow between rectangular end-noses piers, triangular end-noses piers and semicircular end-noses piers, respectively.

From these Figs. it could be noticed that the proportional backwater rise is immediately proportional to the relative value of downstream Froude number (Fr3) and the backwater rise $\mathrm{h}$ decrease as the pier is located further downstream in the curved channel (i.e. increasing $\Theta$ decreases h). At all discharges, the maximum backwater rise occurs for pier at section 0 degree of the curved channel $(\Theta=0)$ and the minimum backwater rise occurs for pier at section 30 degree of the curved channel $(\Theta=30)$. It is clear also from these Figs., values of backwater rise at the curved channel is bigger than those of straight channel. With greater in the quantity of flow, variation between straight channel and curved channel sections begin to be additional significant.

\section{Effect of pier Shape on The backwater Rise}

The influence of geometrical shape of pier end-nose on upstream backwater rise at subcritical flow condition between piers is clarified also in Figs. 5, 6 and 7. From these Figs., it is found that the backwater rise upstream triangular end-noses piers follows the identical trend as in rectangular piers for all pier locations in curved channel and also for straight channel, but the values of backwater rise in issue of triangular end-noses pier are less than those for rectangular ones for the identical flow conditions. The backwater rise for semicircular end-noses pier is smaller than those for both triangular and rectangular end-noses piers, respectively. The reduction in backwater rise for both semicircular and triangular end-noses piers could be reference to their influence in redirecting flow velocities, which decreased the backwater rise. This is certain by the obviously studies carried out by Yarnell (Yarnell, 1934).

\section{Effect of contraction Ratio on The backwater Rise}

Figs. 8, 9 and 10 represent relationship between dimensionless backwater rise (h/d3) and Fr3/Fr3L with different pier locations under subcritical condition for contraction ratios 0.97, 95 and 93, respectively. From Figs., for all different pier locations, the backwater rise may be caused to piers constriction at subcritical flow between piers is aversely proportional to the contraction ratio $\sigma$ for different pier flow conditions. These Figs. shows that the backwater rise is directly proportional to $\operatorname{Fr} 3 / \mathrm{Fr} 3 \mathrm{~L}$ at among values of contraction rate. This could be mention to the increasing in flow quantity occurred from the increasing of Fr3, in which the value of Fr3L is fixed for each value of contraction ratio as clarified in Eq. 7. The excess of flow rate between piers performed in increasing of the backwater rise upstream the bridge site, which is certain from Eq. 8, in which the backwater rise be controlled fundamentally on the value of Fr3.

\section{Compare among the measured and the calculated values}

Figs. 11,12,13 and 14 represent a compare among the measured and the studied values of the dimensionless backwater rise $(\mathrm{h} / \mathrm{d} 3)$ and $\operatorname{Fr} 3 / \operatorname{Fr} 3 \mathrm{~L}$ under subcritical condition at straight channel and sections 0,15 and 30 degree of the curved channel $(\Theta$ $=0^{\circ}, 15^{\circ}, 30^{\circ}$ ).

As it is evident from these Figs, for all different pier locations, the trend of the experimental values of dimensionless backwater rise upstream piers ( $\mathrm{h} / \mathrm{d} 3)$ is approximately similar to the trend of the corresponding predicted ones according Yarnell (Yarnell, 1934) at subcritical flow between piers. The comparatively great variation for the three geometrical shapes of piers down subcritical flow could be mention to the truth that Yarnell Eq. 8 was obtained for a pier length to pier width equal to 4:1 [12], while the pier length to pier width ratio in this study ranges among 5:1 to 10:1. 


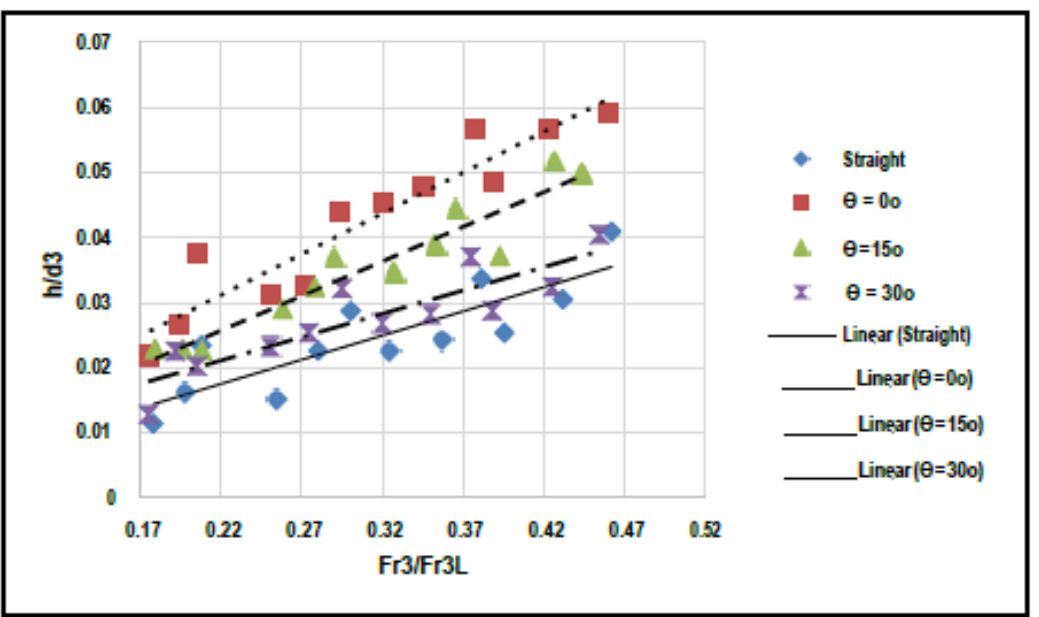

Fig. 5: Relationship between dimensionless backwater rise (h/d3) and Fr3/Fr3L for flow between rectangular end-noses piers with different pier locations under subcritical condition.

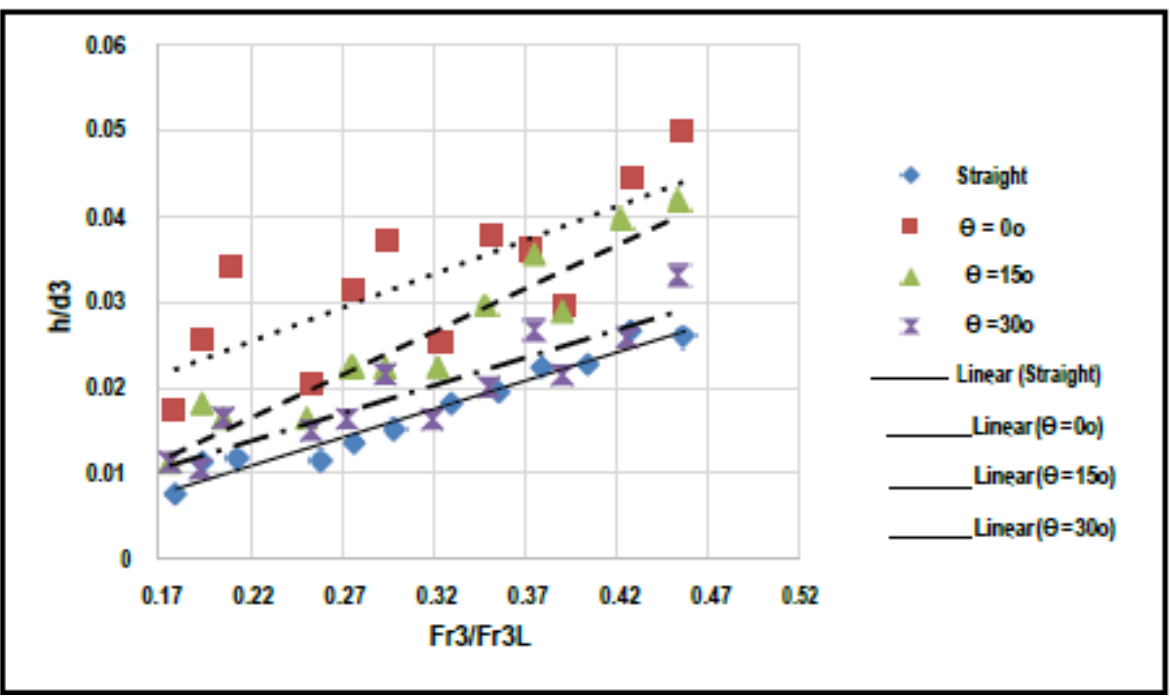

Fig. 6: Relationship between dimensionless backwater rise (h/d3) and Fr3/Fr3L for flow between triangular end-noses piers with different pier locations under subcritical condition.

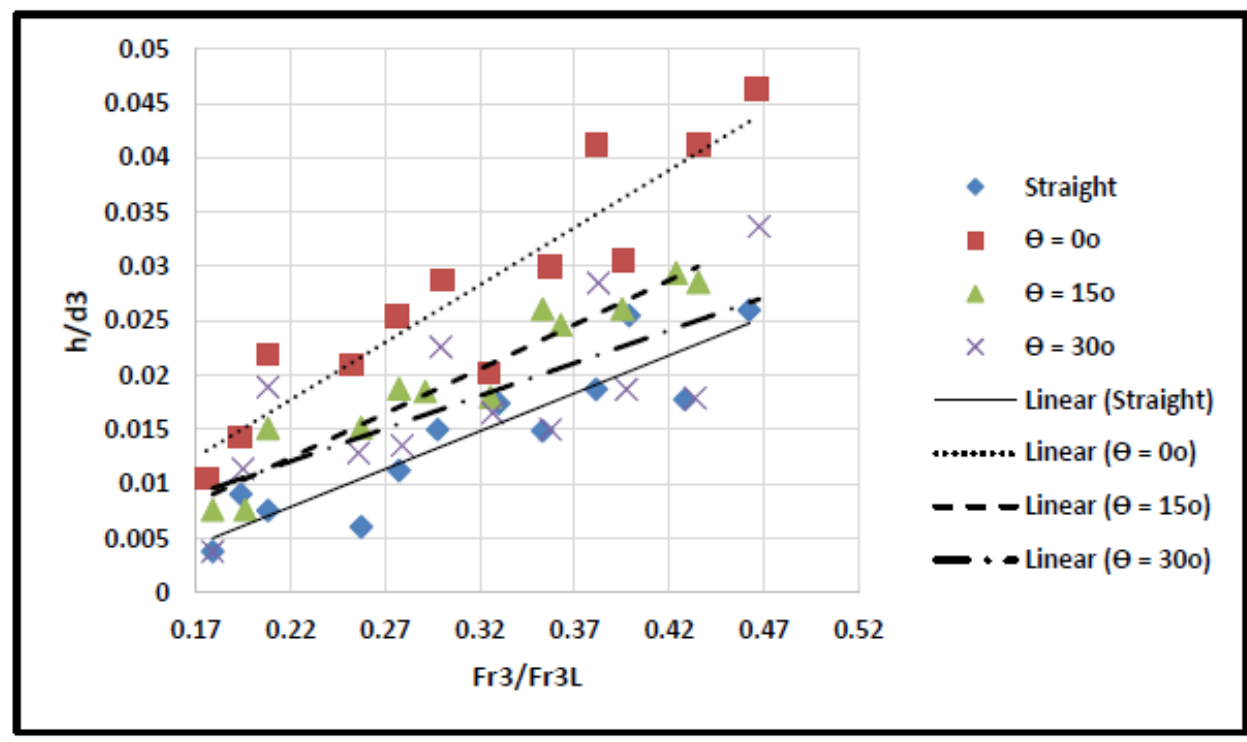

Fig. 7: Relationship between dimensionless backwater rise (h/d3) and Fr3/Fr3L for flow between semicircular end-noses piers with different pier locations under subcritical condition. 
Citation: Amir M. Mobasher and Ahmed H. Mahmoud Backwater Rise Due To Bridge Piers in Curved Channels under Subcritical Flow Conditions. Australian Journal of Basic and Applied Sciences., 13(1): 117-127. DOI: 10.22587/ajbas.2019.13.1.15

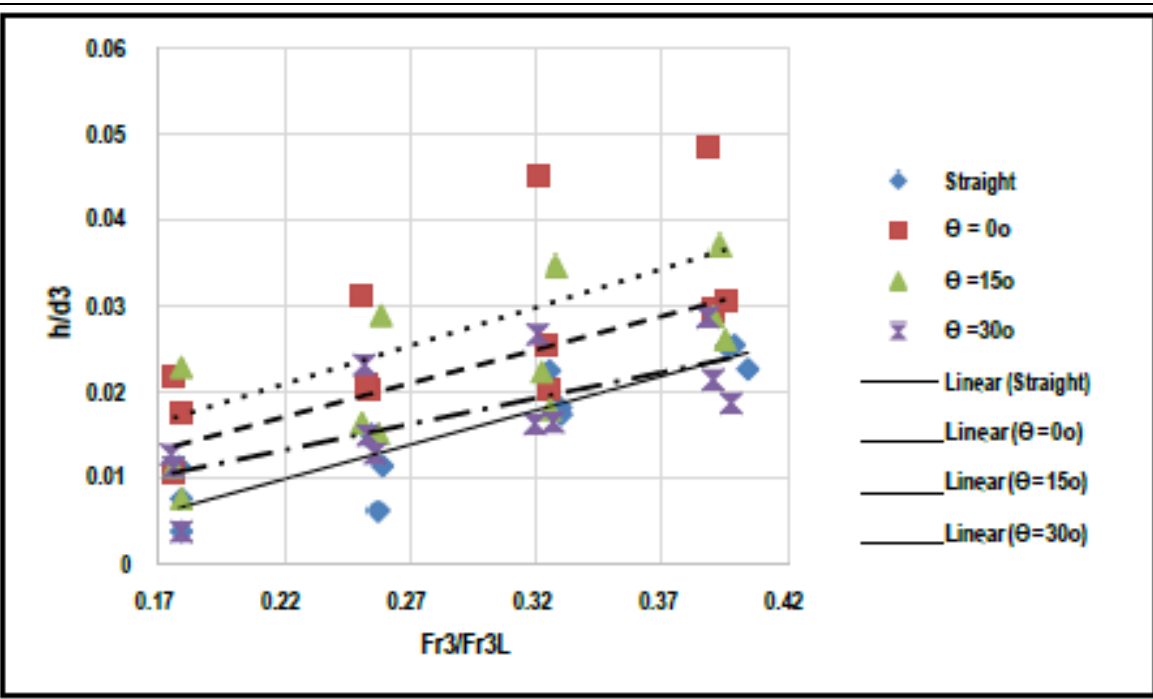

Fig. 8: Relationship between dimensionless backwater rise (h/d3) and Fr3/Fr3L for con- traction ratio 0.97 with different pier positions under subcritical condition.

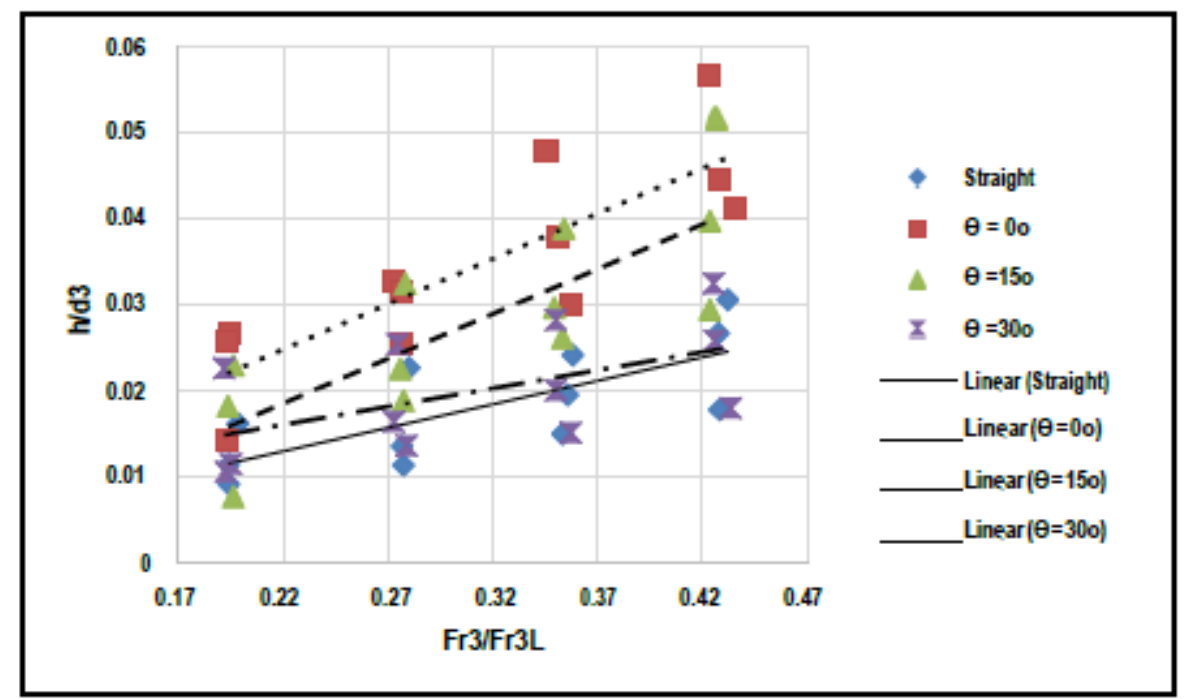

Fig. 9: Relationship between dimensionless backwater rise (h/d3) and Fr3/Fr3L for contraction ratio 0.95 with different pier positions under subcritical condition.

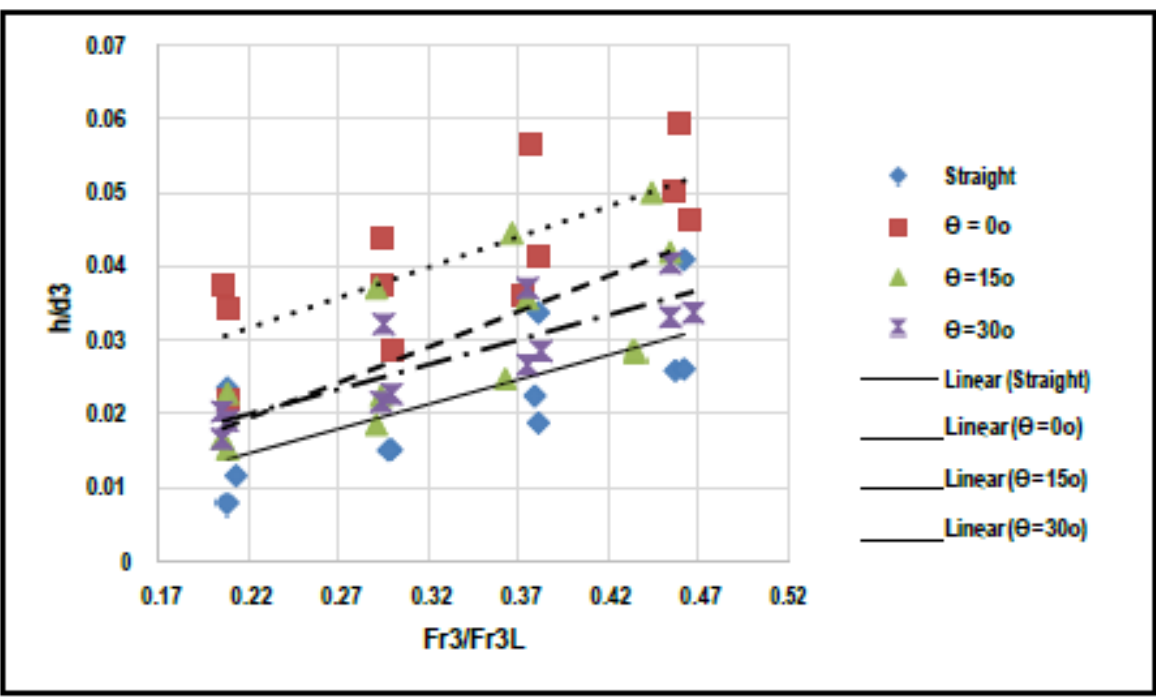

Fig. 10: Relationship between dimensionless backwater rise (h/d3) and Fr3/Fr3L for contraction ratio 0.93 with different pier positions under subcritical condition. 


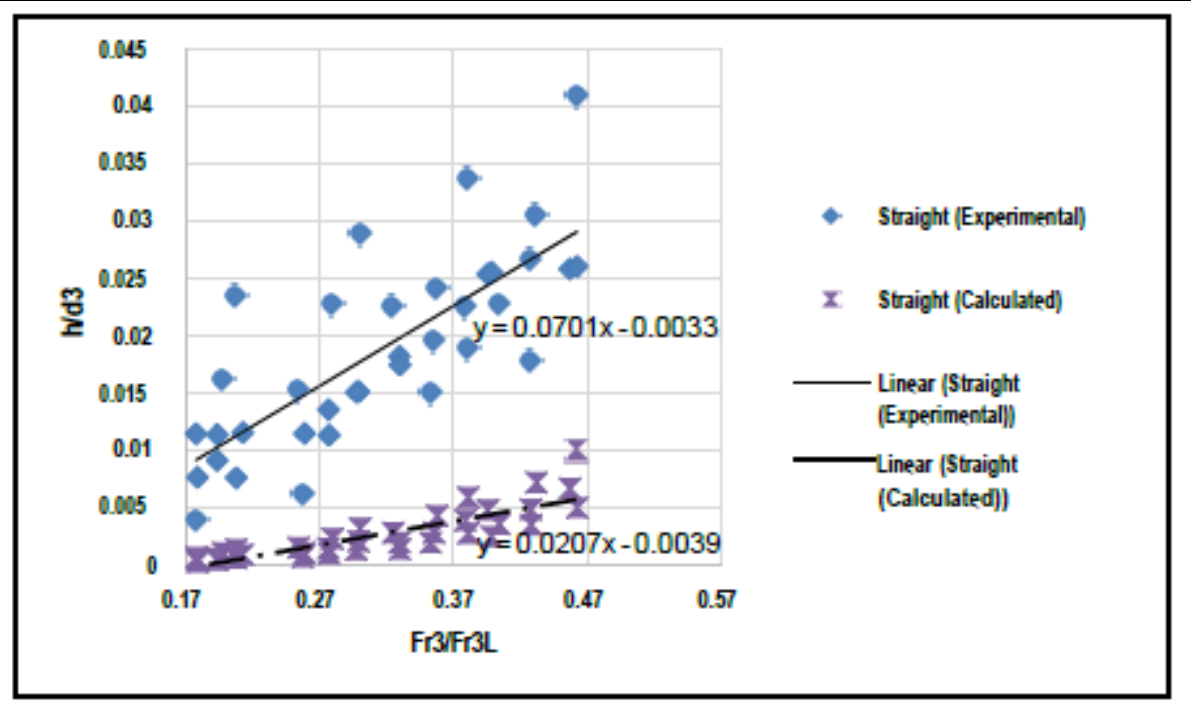

Fig. 11: Relationship between dimensionless backwater rise (h/d3) and Fr3/Fr3L under subcritical condition for straight channel.

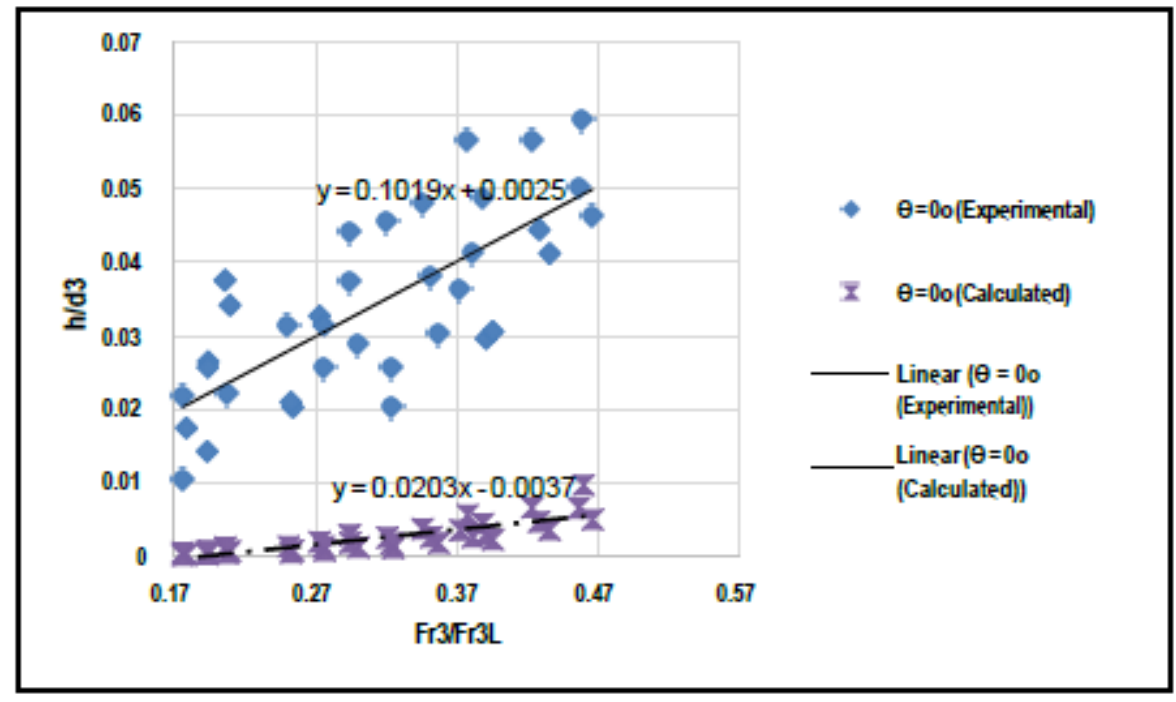

Fig. 12: Relationship between dimensionless backwater rise $(\mathrm{h} / \mathrm{d} 3)$ and Fr3/Fr3L under subcritical condition at section 0 degree of the curvature $\left(\Theta=0^{\circ}\right)$.

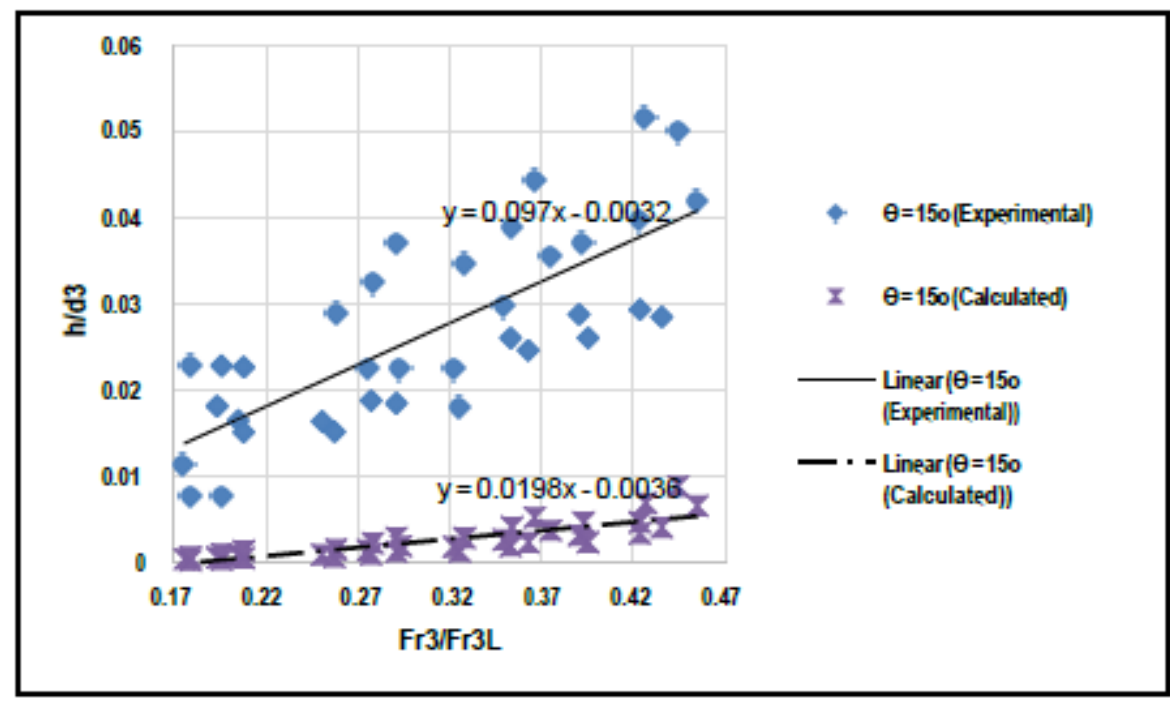

Fig. 13: Relationship between dimensionless backwater rise (h/d3) and Fr3/Fr3L under subcritical condition at section 15 degree of the curvature $\left(\Theta=15^{\circ}\right)$. 


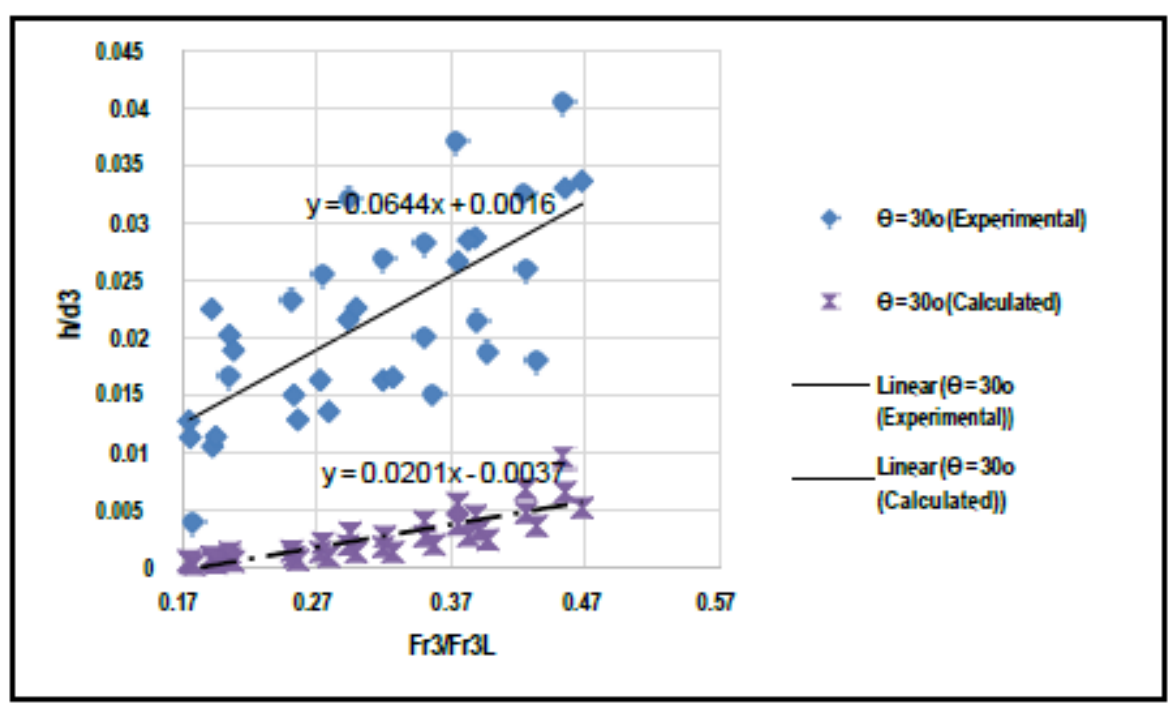

9Fig. 14: Relationship between dimensionless backwater rise (h/d3) and Fr3/Fr3L under subcritical condition at section 30 degree of the curvature $\left(\Theta=30^{\circ}\right)$.

\section{PROPOSED EMPIRICAL EQUATIONS}

Using the experimental data, this yielded the derived linear relations to calculate backwater rise at subcritical flow situation between bridge piers with different pier locations depending on downstream flow properties at bridge site.

$$
\begin{aligned}
& \frac{h}{d_{3}}=0.0701 \frac{F r_{3}}{F r_{3 L}}-0.003 \quad \text { For straight channel } \\
& \frac{h}{d_{3}}=0.1019 \frac{F r_{3}}{F r_{3 L}}+0.0025 \quad \text { For curved channel }(\Theta=0) \\
& \frac{h}{d_{3}}=0.097 \frac{\mathrm{Fr}_{3}}{\mathrm{Fr}_{3 L}}-0.0032 \quad \text { For curved channel }(\Theta=15) \\
& \frac{h}{d_{3}}=0.0644 \frac{F r_{3}}{F r_{3 L}}+0.0016 \quad \text { For curved channel }(\Theta=30)
\end{aligned}
$$

\section{CONCLUSION}

From the above mentioned investigation phases, some conclusions were deduced around the possibility of the implementation of the piers in the curved part in the waterway, also the best shapes and angles of curvature in the channel to reduce the effect of backwater rise upstream piers. The deduced conclusions are summarized, as follows:

1 The backwater rise decreases as the pier is located further downstream in the curved channel. At all discharges, the maximum backwater rise occurs for pier at section 0 degree of the curved channel $(\Theta=0)$ and the minimum backwater rise occurs for pier at section 30 degree of the curved channel $(\Theta=30)$.

2 Values of backwater rise at the curved channel is bigger than those of straight channel. With increasing in the quantity of flow, variation among straight channel and curved channel sections begin to be additional significant.

3 In both curved and straight channels, the backwater rise for semicircular end-noses pier is less than those for both triangular and rectangular end-noses piers, respectively.

4 The backwater rise is immediately commensurate to the proportional value of downstream Froude number and also to aversely proportional to the value of contraction ratio.

5 The backwater rise upstream bridge piers for subcritical flow between piers is inversely commensurate to the value of contraction ratio.

6 The following relationships were advanced for prophecy the backwater rise may be caused to flow contraction by bridge piers at subcritical continuous situation between bridge piers: 


$$
\begin{array}{ll}
\frac{h}{d_{3}}=0.0701 \frac{F r_{3}}{F r_{3 L}}-0.003 & \text { For straight channel } \\
\frac{h}{d_{3}}=0.1019 \frac{F r_{3}}{F r_{3 L}}+0.0025 & \text { For curved channel }(\Theta=0) \\
\frac{h}{d_{3}}=0.097 \frac{F r_{3}}{F r_{3 L}}-0.0032 & \text { For curved channel }(\Theta=15) \\
\frac{h}{d_{3}}=0.0644 \frac{F r_{3}}{F r_{3 L}}+0.0016 & \text { For curved channel }(\Theta=30)
\end{array}
$$

\section{REFERENCES}

Atabay, S., Haji Amou Assar, K., Hashemi, M., \& Dib, M. (2018). Prediction of the backwater level due to bridge constriction in waterways. Water and environment journal, 32(1), 94-103.

Beffa, C. (1996). Backwater computation for transcritical river flows. Journal of Hydraulic Engineering, 122(12), $745-748$.

Charbeneau, Randall J. and Holly, Edward R., "Backwater effects of bridge piers in subcritical flow", Center of Transportation Research, University of Texas, Project Summery Report 1805-S, 2001.

Chow, Ven Te, "Open channel hydraulics", McGraw-Hill, Inc., 1959.

El-Alfy, K. S., " Experimental study of backwater rise due to bridge piers as flow obstructions ", Tenth International Water Technology Conference, Hurghada, Egypt IWTC 10, 2006.

El-Alfy, K. S., " Backwater rise due to flow constriction by bridge piers", Thirteenth International Water Technology Conference, Hurghada, Egypt IWTC 13, 2009.

Henderson, F. M., "Open channel flow”, Macmillan Publishing Co., Inc., New York, 1966.

Hunt, John H. and Brunner, Gary W., "Flow transitions in bridge backwater analy- sis", US Army Crops of Engineering, Institute of Water Resources, 1995.

Kaatz, Kelly, J., " Analysis of alternatives for computing backwater at bridges", Jour- nal of Hydraulics Engineering, Vol. 12, Issue 9, 1997.

Seckin, Galip, "A simple formula for estimating backwater at bridge constriction", Can. J. Civ. Engrg., Vol. 31 (4), 2004.

Smibabu, C. R., Sabansh, R. M., Narasimhan, R., and Chandhni, A. R., " Backwater rise and drag characteristics of bridge biers under sub-critical flow conditions", Eu- ropean Water 36: 27-35, 2011.

Soliman, M.A., "Design of irrigation structures and works", Al-Azhar University, Cairo, Egypt, 1989.

Sturm, Terry W, “Open channel hydraulics” McGraw-Hill Inc., New York, 2001.

Yarnell, D.L., "Bridge piers as channel obstructions”, U. S. Department of Agricul- ture, Tech. Bull. No. 442 , November 1934. 